\title{
The St Vincent Task Force for Diabetes: report of the Cardiovascular Disease Subgroup
}

The St Vincent Declaration was the outcome of a meeting sponsored jointly by the World Health Organisation and the International Diabetes Federation in the Northern Italian town of St Vincent in 1989. Its stated aim was to improve the quality of medical care received by patients with diabetes, in particular the prevention of complications. The declaration gave priority to the establishment of comprehensive and reliable databases detailing the provision of care and its efficacy at both local and national level. Within the United Kingdom a task force, established by the Department of Health and the British Diabetic Association, set up a series of subgroups, which have now reported on several priority areas including cardiovascular disease. ${ }^{1}$

Physicians are familiar with the heavy toll exacted by cardiovascular disease among diabetic patients. Coronary heart disease is two to three times more common among diabetic men and four to five times more common among premenopausal women. ${ }^{2}{ }^{3}$ Myocardial infarction has a higher case fatality in diabetic patients and is responsible for nearly half of all deaths; among survivors heart failure is a more likely sequel than for non-diabetic patients.

At a time of increased interest in the prevention of coronary disease the report provides a reminder of the opportunities for prevention among those who are diabetic. ${ }^{1}$ Although the classic risk factors for coronary disease may have less relative effect in the presence of diabetes an increased absolute risk means that the attributable risk is also greater. Cigarette smoking and hypertension merit particular attention by health professionals in regular contact with diabetic patients particularly in primary care and diabetic clinics. It has been calculated that stopping cigarette smoking would reduce coronary heart disease deaths by $15 \%$ and effective control of hypertension by $6 \% .^{4}$ Control of hypertension also slows the deterioration of renal function caused by diabetic nephropathy. The report of the cardiovascular subgroup was prepared before publication of two studies which demonstrate the benefit of HMG Co-A reductase inhibitors ${ }^{56}$ and so the value of treating moderate hyperlipidaemia in the prevention of coronary disease among diabetic patients may have been underestimated. ${ }^{7}$ The ongoing Heart Protection Study will provide additional guidance on the value of statins among diabetic patients with and without overt evidence of vascular disease, although isolated hypercholesterolaemia is not the most frequent lipid abnormality encountered in diabetes mellitus and so other lipid-lowering drugs may play a more important part.

The cardiologist is addressed most specifically on the management of symptomatic coronary disease which is

\section{Glossary}

GUSTO-1 = Global Utilization of Streptokinase and Tissue Plasminogen Activator for Occluded Coronary Arteries HMG CoA = 3-hydroxy-3-methylglutaryl coenzyme A considered to have been influenced by some misconceptions. Fear of intraocular haemorrhage from advanced diabetic retinopathy has often lead to withholding of thrombolytic drugs in the treatment of myocardial infarction; there is, however, little evidence to substantiate such fear. ${ }^{8}$ Recent subgroup analysis of intervention trials shows that thrombolytic therapy is highly effective among diabetic patients, with the substantial reduction in mortality being likely to outweigh any risk of eye damage. In the GUSTO-1 study, there was only one ocular haemorrhage in 6011 diabetic patients given thrombolysis, and that was periobital and not retinal. ${ }^{9}$

Physicians are sometimes reluctant to use $\beta$ blockers after myocardial infarction among diabetic subjects in case the symptoms of hypoglycaemia are masked and spontaneous recovery impeded. $\beta$ Blockade has however been shown to reduce reinfarction and coronary mortality in people with diabetes ${ }^{10}$ although caution must be used in recommending these drugs to patients with peripheral vascular disease, or in using non-selective $\beta$ blockers in insulin-treated patients. Coronary artery disease in diabetic patients is often judged likely to be diffuse, severe, and unsuited to surgery. Angiographic and necropsy evidence on this matter is inconclusive ${ }^{11} 12$ but coronary atherosclerosis may progress more rapidly in the presence of diabetes. ${ }^{13}$ Angiographic appearances of advanced and extensive disease may therefore be the result of delay in investigation. Although surgery may be more often complicated by infection, symptom relief by coronary bypass surgery, including internal mammary grafting, is comparable to that achieved among non-diabetic patients but long-term survival is less good. ${ }^{14-16} \mathrm{~A}$ reduced long-term survival does not of itself justify withholding surgery from diabetic patients. Similarly, diabetic patients with angina experience good results from angioplasty, although there is some suggestion of a higher incidence of restenosis ${ }^{17}$ even when stents have been used. ${ }^{18} 19$ A recent subgroup analysis of a large revascularisation study for multivessel disease, however, showed a substantially higher five year mortality in diabetic patients after angioplasty than after bypass grafting, a finding which led the United States National Heart Lung and Blood Institute to issue a clinical alert. ${ }^{20}$

The report calls for more active consideration of revascularisation procedures for diabetic patients by cardiologists and cardiac surgeons, as well as reminding physicians and general practitioners of the potential for prevention of vascular disease. ${ }^{1}$ It acknowledges the financial consequences of such a policy and in doing so sends a clear message to those responsible for the purchase of care that the cost of such provision should be properly addressed in any contract for the comprehensive medical care of diabetic members of society.

British Heart Foundation,

BRIAN PENTECOST

London $W 1 \mathrm{H} 4 \mathrm{DH}$

Whittington Hospital,

JOHN S YUDKIN 
1 St Vincent Joint Task Force for Diabetes: The Report. Department of Health and British Diabetic Association, 1995.

2 Fuller JH, Shipley MJ, Rose G, Jarrett RJ, Keen H. Coronary heart disease risk and impaired glucose tolerance. The Whitehall Study Lancet 1980; i:1373-6.

3 Rosengren A, Welin L, Tsipogianni A, Wilhelmsen L. Impact of cardiovascular risk factors on coronary heart disease and mortality among middle aged diabetic men: a general population study. $B r$ Med $f$ 1989; 299:1127-31.

4 Yudkin JS. How can we best prolong life? The benefits of coronary risk factor reduction in non-diabetic and diabetic subjects. $\mathrm{Br} M e d \mathcal{F} 1993$; factor reductio

5 Scandinavian Simvastatin Survival Study Group. Randomised trial of cholesterol lowering in $\mathbf{4 4 4 4}$ patients with coronary heart disease. The Scandinavian Simvastatin Survival Study. Lancet 1994;344: 1383-99.

6 Shepherd J, Cobbe SM, Ford I, Isles CG, Lorimer AR, MacFarlane PW. Prevention of coronary heart disease with pravastatin in men with hypercholesterolaemia. N Engl Y Med 1995;333:1301-7.

7 Pyörälä K, Pedersen TR, Kjekshus J. The effect of cholesterol lowering with simvastatin on coronary events in diabetic patients with coronary heart disease. Diabetes 1995;443(suppl 1)35A.

8 Ward H, Yudkin J. Thrombolysis in patients with diabetes. BMF 1995; 310:3-4.

9 Mahaffey KW, Granger CB, Stebbins AL, Calitt RM. Diabetic retinopathy should not be a contraindication to thrombolytic therapy: Quantification of risk in 6011 patients. Circulation 1995;92:1-417.

10 Malmberg K, Herlitz J, Hjalmarson A, Ryden L. Effects of metoprolol on mortality and late infarction in diabetes with suspected acute myocardial infarction. Retrospective data from two large studies. Eur Heart $\mathcal{f}$ 1989;10:423-8.

11 Kanojia A, Kasliwal R, Seth A, Bhandari S, Kler TS, Bhatia ML. Clinical and coronary arteriographic features and outcome of recent onset unstable angina. Int $\mathcal{F}$ Cardiol 1993;39:173-80.

12 Bhan A, Das B, Wasir HS, Kaul U, Venugopal P. Profile of coronary arterial disease in diabetic patients undergoing coronary arterial bypass grafting. Int $\mathcal{f}$ Cardiol 1991;31:155-9.

13 Alderman EL, Corley SD, Fisher LD, Chaitman BR, Faxon DP, Guyton RA. Five-year angiographic follow-up of factors associated with the progression of coronary artery disease in the Coronary Artery Surgery Sression of coronary artery disease in the Cord 1 . $\mathrm{Am}$ Coll Cardiol 1993;22:1 141-54.

14 Lawrie GM, Morris GC Jr, Glaeser DH. Influence of diabetes mellitus on the results of coronary bypass surgery. Follow-up of 212 patients, ten to the results of coronary bypass surgery. Follow-up of 212 patients, ten to
15 years after surgery. $f A M A 1986 ; 256: 2967-71$.

15 Rahimtoola SH, Bennett AJ, Grunkemeier GL, Block P, Starr A. Survival at 15-18 years after coronary bypass surgery for angina in women. at $15-18$ years after cor
Circulation 1993;88:71-8.

16 Accola KD, Jones EL, Craver JM, Weintraub WS, Guyton RA. Bilateral mammary artery grafting: avoidance of complications with extended mammary artery grafting: avoidance of

17 Rensing BJ, Hermans WRM, Vos J, Tijssen JGP, Rutch W, Danchin N. Luminal narrowing after percutaneous transluminal coronary angioplasty: A study of clinical, procedural, and lesional factors

18 Corruzza JP Jr, Kuntz RE, Fisherman RF, Baim DS. Restenosis after arterial injury caused by coronary stenting in patients with diabetes mellitus. Ann Intern Med 1993;118:344-9.

19 Hearn JA, King SB III, Douglas JS, Carlin SF, Lembo NJ, Chazzal ZMB. Clinical and angiographic outcomes after coronary artery stenting for acute or threatened closure after percutaneous transluminal coronary angioplasty. Initial results with a balloon-expandable, stainless steel design. Circulation 1993;88:2086-96.

20 Ferguson JJ. NHBI BARI. Clinical alert on diabetes treated with angioplasty. Circulation 1995;92:3371. 